\section{Mascarilla N95: una medida útil en la prevención de la tuberculosis pulmonar}

\author{
N95 mask a useful measure in the \\ prevention of pulmonary tuberculosis
}

Castañeda-Narváez JL, Hernández-Orozco HG

\section{INTRODUCCIÓN}

La tuberculosis es una enfermedad que implica un riesgo ocupacional para el personal de salud que atiende a este tipo de pacientes, debido a que el agente Mycobacterium tuberculosis es eliminado hacia el ambiente a través de diferentes acciones como la tos, el estornudo, el acto de escupir, cantar o incluso la conversación. Las pequeñas gotas que se generan se evaporan rápidamente y se convierten en aerosoles de pequeñas partículas que, por su tamaño (1 a $3 \mu \mathrm{m})$, permanecen en suspensión y pueden ser transportadas, según el flujo del aire, a través de la habitación o de un edificio. El tamaño reducido facilita su llegada a los alvéolos pulmonares y el riesgo de transmisión está confinado a los que comparten lugares cerrados y mal ventilados, debido a la gran concentración de aerosoles en ese espacio.

Las precauciones específicas de aislamiento por vía aérea para tuberculosis incluye el uso de mascarilla N95; ésta se utiliza para proteger a los trabajadores, pacientes, familiares y visitantes.

Sabemos que todo paciente con tuberculosis de localización pulmonar que expectore; tuberculosis laríngea; paciente con cavitación en pulmón, con resultado de baciloscopias o cultivo positivos, que no ha recibido tratamiento adecuado, que se someta a procedimientos como broncoscopia, aplicación de medicamentos por aerolización o inducción de esputo es un potencial riesgo de diseminar la infección, por lo que se debe usar la mascarilla N95 mientras se encuentren en la habitación
Infectólogo Pediatra.

Instituto Nacional de Pediatría, Ciudad de México.

Recibido: 16 de enero del 2017

Aceptado: 19 de enero del 2017

Correspondencia

Dr. José Luis Castañeda Narváez

drcastanedan@yahoo.com

Este artículo debe citarse como

Castañeda-Narváez JL, Hernández-Orozco HG. Mascarilla N95: una medida útil en la prevención de la tuberculosis pulmonar. Acta Pediatr Mex. 2017;38(2):128-133.

DOI: http://dx.doi.org/10.18233/APM38No2pp128-1331365 
del paciente con este diagnóstico. Este escrito busca explicar y difundir el procedimiento de uso de mascarilla o respirador N95 para estandarizar su uso y lograr su función protectora.

\section{RIESGO EN NIÑOS}

En general, los niños pequeños con tuberculosis pulmonar son menos propensos que los adultos a ser infecciosos, esto debido a que a veces los infantes son incapaces de producir esputo al toser, o pueden tener tuberculosis paucibacilar; sin embargo, pueden trasmitir M. tuberculosis si sus basiloscopias son positivas o tienen una radiografía con cavitación.

Todo paciente con tuberculosis de localización pulmonar es un potencial riesgo de diseminar la infección, por lo que el uso de mascarilla N95 mientras se esté en contacto con el paciente es una medida de protección que debe seguirse durante todo el tiempo.

La aplicación de las precauciones estándar se determina de acuerdo a la identificación de riesgos de los procedimientos para prevenir la exposición de los trabajadores de salud, pacientes y familiares a potenciales infecciones; sin embargo, cuando se tiene identificada una infección, o la probable infección en un paciente, se utilizan precauciones específicas de aislamiento.

El uso de las precauciones específicas de aislamiento de vía aérea para pacientes con tuberculosis deben anteceder las actividades de atención médica y son barreras que evitan la transmisión de los agentes patógenos. Se listan a continuación:

- Higiene de manos.

- Equipo protector personal: guantes, bata, máscara, lentes o gafas de protección.
- Uso de mascarilla N95 antes del ingreso al cuarto del paciente.

- Cuarto individual, mantener la puerta cerrada.

- Idealmente cuartos de presión negativa.

- El recambio de aire en los cuartos debe ser mínimo de 12 veces por hora.

Las recomendaciones adicionales que deberá de utilizar el personal de salud (médicos y enfermeras) o las personas que tiene mayor contacto con el paciente con tuberculosis pulmonar incluyen:

- Uso de guantes no estériles en caso de manejo de secreciones.

- Traslade al paciente lo menos posible, en caso de ser necesario notifique al servicio correspondiente.

- Coloque previamente mascarilla N95 al paciente.

- Colóquese usted y el personal encargado del trasporte o manejo del paciente la mascarilla N95.

- Programe al paciente para realización de estudios ya sea al inicio o al final del turno indicando limpieza del área posterior a éstos.

- Utilizar material y equipo de uso exclusivo para el paciente y que no lo comparta con otros pacientes.

- Al egreso del paciente solicite limpieza exhaustiva del área, así como desinfección del equipo utilizado con el paciente.

\section{CARACTERÍSTICAS DE LA MASCARILLA N95}

La mascarilla respiratoria N95 impide el paso del aire con partículas muy pequeñas de bacterias 
como tuberculosis o virus del sarampión. La mascarilla N95 impide el paso de estos microbios.

El uso de mascarilla N95 cumple con las directrices de los Centers for Disease Control and Prevention (CDC) para el control de la exposición a la tuberculosis: como un respirador de partículas desechable que está destinado a ayudar a reducir la exposición del usuario a ciertas partículas en el aire; una máscara quirúrgica, está diseñada para ser resistente a las salpicaduras de fluido y las salpicaduras de sangre y otros materiales infecciosos. Las características incluyen: N95 aprobado por $\mathrm{NIOSH}$ 42. CFR.84 cumple con las guías del CDC para el control de la exposición a Mycobacterium tuberculosis, aprobado por la Food and Drug Administration (FDA) para su uso de acuerdo a la norma ASTM F2101 resistente al fluido. Esta mascarilla no contiene componentes hechos de látex, es de caucho natural con un diseño en forma de taza resistente al colapso, bandas trenzadas, espuma de amortiguación para la nariz y su construcción es en peso ligero para uso cómodo.

\section{¿Cómo utilizo una mascarilla respiratoria N95?}

Antes de ponerse la mascarilla N95 deber tener las siguientes consideraciones:

- La mascarilla se tiene que ajustar bien sobre la cara para prevenir que los microbios entren. Las mascarillas vienen en diferentes tamaños. Utilice la mascarilla que se ajuste más apretadamente a su cara.

- Será necesario utilizar la mascarilla de la manera correcta cada vez que visite a la persona enferma o no le protegerá de los microbios. Si la mascarilla no le queda bien usted también podrá enfermarse.

- Póngase la mascarilla antes de entrar en el cuarto con la persona enferma.
- No se quite la mascarilla hasta que esté fuera del cuarto de la persona enferma y la puerta esté cerrada.

- La mascarilla respiratoria no le protege si se ensucia o si se moja, por lo que si sucede ésto póngase una mascarilla limpia.

- Si usted empieza a tener mareos o dificultad para respirar, salga del cuarto de la persona enferma y quítese la mascarilla.

- Póngase la mascarilla antes de volver a entrar al cuarto donde está la persona enferma.

- Cuando se retire del cuarto del paciente tire la mascarilla al contenedor de desechos fuera del cuarto de la persona enferma.

- Use una mascarilla nueva cada día que visite a la persona enferma.

No se recomienda el uso de mascarillas quirúrgicas ya que no proveen la protección adecuada, estas mascarillas son una barrera de protección para grandes gotas y no son efectivas para filtrar pequeñas gotas y partículas del aire, ni previenen la entrada de ésta alrededor de la mascarilla cuando la persona que la usa inhala, por lo que no deben usarse en los sitios donde se encuentra un paciente con tuberculosis.

\section{Cuadro 1.}

\section{Uso extendido}

Se refiere a la práctica de usar el mismo respirador N95 para encuentros repetidos de contacto cercano con varios pacientes, sin quitar el respirador entre los encuentros del paciente. El uso extendido puede ser implementado cuando varios pacientes están infectados con el mismo patógeno respiratorio y los pacientes se colocan juntos en salas de espera o salas de hospitalización. Se ha recomendado el uso prolongado como una opción para conservar respiradores 
Cuadro 1. Procedimiento para ponerse la mascarilla N95

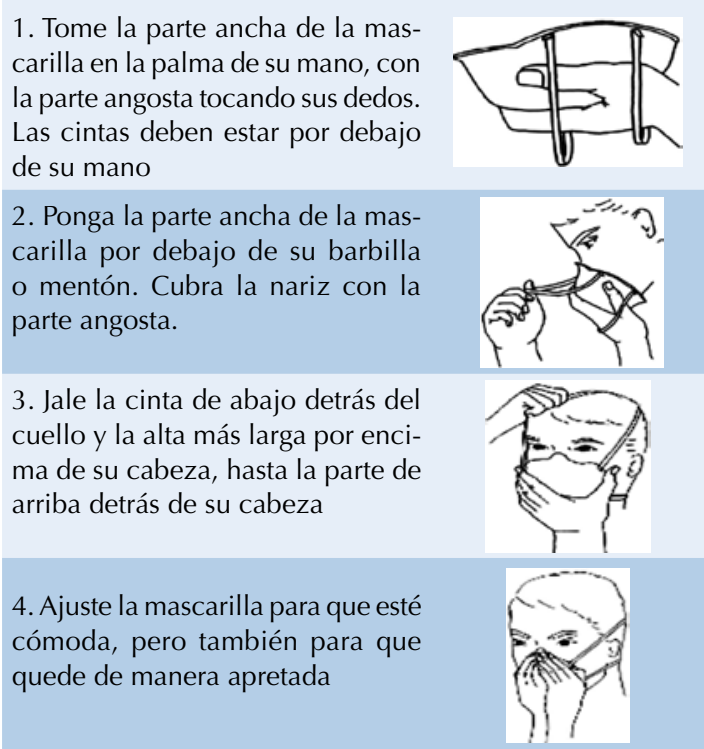

durante brotes y pandemias de patógenos respiratorios previos.

\section{Reutilización de mascarilla o respirador N95}

Se refiere a la práctica de usar el mismo respirador N95 para encuentros múltiples con los pacientes y removerlo después de cada encuentro al salir de la habitación. El respirador se almacena entre los encuentros para ser puesto de nuevo antes del siguiente encuentro con un paciente. Para los agentes patógenos en los que la transmisión de contacto (por ejemplo, los fómites) no es una preocupación; la reutilización no urgente se ha practicado durante décadas. Por ejemplo, para la prevención de la tuberculosis, los Centers for Disease Control and Prevention recomiendan que un respirador clasificado como desechable pueda ser reutilizado por la misma persona. Incluso cuando se practica o recomienda la reutilización del respirador N95 existen restricciones que limitan el número de veces que se reutiliza; de modo que la reutilización del respirador N95 se refiere a menudo como "reutilización limitada". Ésta ha sido recomen- dada y ampliamente utilizada como una opción para conservar los respiradores durante brotes y pandemias de patógenos respiratorios previos $\mathrm{O}$ cuando hay escasez de recursos.

La reutilización segura de N95 se ve afectada por una serie de variables que afectan la función del respirador y la contaminación a lo largo del tiempo, por lo que debe descartarse antes de que se convierta en un riesgo significativo para la transmisión o se reduzca su funcionalidad.

Se debe limitar la posible contaminación de la superficie del respirador N95 (por ejemplo el uso de barreras para evitar la contaminación por pulverización de gotas):

- Indicar al personal que refuerce la necesidad de minimizar el contacto innecesario con la superficie del respirador.

- Estricta observancia de las prácticas de higiene de las manos y la adecuada técnica de colocación y desmontaje del respirador.

- Deseche los respiradores N95 después del uso durante los procedimientos de generación de aerosol.

- Deseche los respiradores N95 contaminados con sangre, secreciones respiratorias o nasales u otros fluidos corporales de los pacientes.

- Deseche los respiradores N95 después de un contacto cercano con cualquier paciente coinfectado con una enfermedad infecciosa que requiera precauciones de vía aérea.

- Deseche cualquier respirador que esté obviamente dañado o cuando se vuelva difícil respirar.

- Utilice una máscara que pueda limpiarse o una máscara quirúrgica sobre un respi- 
rador N95 para reducir la contaminación superficial del respirador.

- Cuelgue los respiradores usados en un área de almacenamiento designada o guárdelos en un recipiente limpio y transpirable, como una bolsa de papel entre usos.

- Empaque o almacene los respiradores entre usos para que no se dañen o deformen. Los recipientes de almacenamiento deben eliminarse o limpiarse regularmente.

- Para minimizar la posible contaminación cruzada almacene los respiradores para que no se toquen entre sí y la persona que usa el respirador está claramente identificada.

Nunca guarde respiradores desechables en bolsillos, bolsas de plástico u otras áreas confinadas. En esas situaciones se necesita cuidado al retirar y almacenar el equipo de protección personal para evitar contaminar la piel, la ropa y las membranas mucosas. Retire el respirador y colóquelo en un área designada o colóquelo en una bolsa.

Los respiradores N95 sólo deben ser utilizados por un solo usuario. Para evitar el intercambio accidental de respiradores etiquete los recipientes utilizados para el almacenamiento de respiradores o el respirador en sí (entre usos con el nombre del usuario para reducir el uso accidental del respirador de otra persona).

Realice higiene de las manos con agua y jabón o un desinfectante de base alcohólica para manos antes y después de tocar o ajustar el respirador (si es necesario para comodidad o para mantener el ajuste).

Evite tocar el interior del respirador. Si se hace contacto inadvertido con el interior del respi- rador, realice la higiene de las manos como se describe anteriormente.

Utilice un par de guantes limpios (no estériles) cuando use un respirador N95 usado. Deseche los guantes después de que se use el respirador N95 y se realicen los ajustes necesarios para asegurar que el respirador esté cómodamente sentado en su cara.

Si no se dispone de instrucciones del fabricante, se sugieren limitar el número de reutilizaciones a no más de cinco usos por dispositivo para garantizar un margen de seguridad adecuado.

La experiencia indica que los respiradores pueden funcionar dentro de sus especificaciones de diseño durante 8 horas de uso continuo o intermitente. Algunos estudios de investigación han reclutado trabajadores de la salud como sujetos de prueba y muchos de esos sujetos han usado con éxito un respirador N95 en el trabajo durante varias horas antes de que necesitaran eliminarlos. Por lo tanto, la longitud máxima de uso continuo en lugares de trabajo de salud suele ser dictada por preocupaciones higiénicas (por ejemplo, el respirador se descartó porque se contaminó) o consideraciones prácticas (por ejemplo, necesidad de usar el baño en lugar de un número predeterminado de horas).

Inspeccione el dispositivo para daño físico (por ejemplo, ¿están las correas estiradas tanto que ya no proporcionan suficiente tensión para que el respirador selle a la cara?, ¿están rotas las piezas de la nariz u otras mejoras de ajuste?, etc.).

\section{¿QUÉ OTRAS PRECAUCIONES SE DEBEN TOMAR?}

Como se mencionó, la mascarilla se debe ajustar bien sobre la cara para prevenir que los microbios entren por los lados. Puede ser necesario el afeitarse el pelo de la cara para que la mascarilla 
se ajuste bien. Si la cara tiene pelo en cantidad abundante (barba crecida, bigote crecido) la mascarilla puede no ajustarse perfectamente.

\section{LECTURAS RECOMENDADAS}

1. González SN, Hernández $\mathrm{OH}$, Castañeda NJ. Control delas infecciones en hospitales pediátricos asociadas a la atención en Salud (IAAS), 3a ed. Trillas, 2016.

2. CDC. Guidelines for preventing the transmission of Mycobacteriumtuberculosis in health-care settings, 2005. MMWR Recomm Rep. 2005;54(17):1-141.

3. Fica AC, Cifuentes MD, Ajenjo NC. Tuberculosis en el personal de Salud. Rev. Chil Infectol. 2008;25(4):243-255.

4. WHO 2002 Guidelines on prevention and control of hospital associated infections.
5. National evidence guidelines for preventing healtcare associated infections in NHS Hospital in England. J Hosp Infect 2007:65;S1-S64.

6. Boyce JM, Pittet D. Guidelines for hand hygiene in health care settins. Recomendations of healthcare infection control practices advisory comite and the HICPAC/SHEA/APIC/ IDSA Hand hygiene task force.

7. Siegel JD, Rhinehart E, Jackson M et al. 2007 Guideline for Isolation Precautions: Preventing Transmission of Infectious Agents in Healthcare Settings Disponible en: https://www. cdc.gov/hicpac/pdf/isolation/Isolation2007.pdf

8. Recommended Guidance for Extended Use and Limited Reuse of N95 Filtering Facepiece Respirators in Healthcare Settings. Disponible en: https://www.cdc.gov/niosh/ topics/hcwcontrols/recommendedguidanceextuse.html 